\title{
Integrating Curriculum: Developing Student Autonomy In Learning In Higher Education
}

\author{
Ulku Yuksel, University of Sydney, Australia
}

\begin{abstract}
The need to combine social constructivist activities with cognitive constructivist ones has emerged which incorporates personalized learning approaches. Characteristics of education and educational institutions of the third millennium indicate that flexibility, inclusiveness, collaboration, authenticity, relevance and extended institutional boundaries are the leading features of superior education. While educational goals have changed and expanded to incorporate lifelong learning, global interaction, the attainment of meta-cognitive knowledge and abilities, so did the role of both students and teachers (Felix, 2005). This study is about various techniques used in curriculum development, teaching and assessment, one of which is the negotiated curricula. How to integrate this phenomenon of the learning and teaching literature into curriculum and its influence on students' active learning is presented.
\end{abstract}

Keywords: Curriculum development, Assessment method, Negotiated curricula, Higher education, International marketing course

\section{INTRODUCTION}

$\mathscr{Q}$ $\mathrm{n}$ analysis of the characteristics of education and educational institutions of the third millennium indicates that flexibility, inclusiveness, collaboration, authenticity, relevance and extended institutional boundaries are the leading features of superior education. While educational goals have changed and expanded to incorporate lifelong learning, global interaction, the attainment of meta-cognitive knowledge and abilities, so did the role of both students and teachers (Felix, 2005). Accordingly the need to combine social constructivist activities with cognitive constructivist ones has emerged which incorporates personalized learning approaches, such as the use of the negotiated curricula.

Previous research supports that the use of negotiated curricula enhances and encourages student learning. The learning on the programme that used negotiated curricula was transformative in that it altered how students become aware of their own capabilities and their potential to advance their work. Students planned, and monitored their learning activities in a way that considerably improved motivation and increased academic standards. The learning achieved led to a positive conversion of personal and professional perspective on the part of the students leading to superior personal self-sufficiency (McMahon, 2010).

Before starting to implement negotiated curricula into their programme, teachers need to start with goals for learning rather than initially attempting to correlate subject areas around a central topic. "In a negotiated curriculum, students have the freedom to make choices, to create personal meaning, to see curriculum as connected to something relevant, and to maintain control of their learning" (Davenport, Jaeger, and Lauritzen, 1995, p. 61). Accordingly, "Students' choices allow them to develop not only as readers and writers, but also as creators, planners, questioners, experimenters, and performers. They have opportunities to be self-directed; to think in various disciplines needed to pursue their inquiry; to develop different intelligences; to interact with others as teacher and learner" (Davenport, Jaeger, and Lauritzen, 1995, p. 61).

The use of the negotiated curricula is important because we educators face several challenges with regard to designing a curriculum. One challenge is about the emphasis we put on some content (significant parts from our perspective) of a subject matter which may not exactly fit into students' interests and motivation. This is especially 
important if the course is an elective one. Another challenge we face is about initiating students' active learning process in order to generate deep learners with a not necessarily always-very-interesting topic from students' perspectives. And finally, we may receive some criticism from students about our various assessment styles in which they mourn that the very assessment was not effectively measuring what they have actually learned and know. Under these circumstances a big question arises: How are we going to activate students' deep learning process?

Specifically, students often bemoan the fact that the assessment style (including but not limited to the style of questions of an assessment) employed in a course doesn't effectively measure what they really know or have studied so hardly. Specifically, they complain about the method of a particular assessment declaring that it does not allow them to demonstrate their accumulated knowledge properly. A second bulk of students' objection and complaint is about the emphasis put by the educator towards some specific parts of a course or a subject matter which does not necessarily match students' different interests and rationale in selecting an elective course. Hence, as educators in business and marketing we face a constant challenge of keeping our subject matter interesting, motivating, attractive, meaningful and content while holding our assessments relevant and up-to-date.

A blend of institutional, cultural, societal, and economic triggers has influenced and caused the emergence of main amendments in higher education, reflected in innovative and student-focused teaching and assessment styles. Due to diversity in students capabilities one cannot presume that all students will learn at the same level by the same teaching styles (Honey and Mumford, 1986; Houghton 2004; Kolb1984). Furthermore, students' capacity and knowledge cannot be assessed by one-size-fit-all type assessments as different people learn in different ways and different people exhibit different abilities concerning knowledge dissemination. Educational objectives embrace all-time learning, worldwide interaction, meta-cognitive knowledge and capabilities. Hence, some new and different processes have to be employed. One of the key processes is Negotiated Curricula (Anderson, Boud and Sampson, 1988; Boud, 1988; Brew and Barrie, 1999; Davenport, Jaeger, and Lauritzen 1995; Felix, 2005; Knowles, 1975). This process highlights the difference of novel education understanding from the traditional teaching perspectives and will enhance the characteristics of contemporary education which include flexibility, breadth, cooperation, authenticity, relevance and wide-ranging organizational borders (Felix, 2005). This paper discusses the use of negotiated curricula in students' assessments and explores student perceptions to such an assessment approach in the context of students enrolled in a recent international marketing course at the University of Sydney.

All these aspects of challenges which educators as well as students encounter indicate the significance of curriculum-decision-making processes. One solution is the employment of the negotiated curriculum theory into practice as the progressive education debate has prompted in the field of development of new theories in curriculum design (Hodgkin, 2007). This new theory suggests curricula developed using negotiation techniques (with the academic institution and students) in line with this new school of thought. According to this theory and the very nature and concept of negotiated curricula, students are invited to contribute to and adjust the curriculum of a given subject matter. In this concepts all stakeholders; that is, the institution, the educator and the students, are given an opportunity to articulate their perceptions including their needs and wants and work cooperatively to attain an outcome that is acceptable, satisfactory and a desired goal for all parties involved (Boomer, 1992). It should be noted that a major element of the negotiated curriculum is that it is set in an abounding socio-political context involving constrains of classroom and institutional possibilities. However, in order for quality education to be provided equitably, these decision-making processes must be clear, apparent, transparent, wide-ranging, acceptable, and participatory (Hodgkin, 2007) by all parties involved.

In all sorts of negotiations, the key part reflects the ownership principle. This principle is the heart of the concept of a negotiated curriculum because it makes all parties own the decision that is made as they all participate in the decisions-making process. The ownership principle declares that individuals are inclined to work hard for things they care for, want and wish to own or they've already owned (i.e., they long for maintaining the ownership which they already have). Accordingly, the result of negotiation triggers the rules of the ownership principle as it generates a sense of ownership. The outcome of this active, deliberate, planned, indented, and participatory participation in the decision-making progression creates deep-learners rather than surface learners. Deep learners are better learners than surface learners and this, created via negotiation, brings a more liberal and enlightened learning environment into classrooms as students are no longer passive, obedient audience of a "teacher's imposed pedagogical pattern" (Boomer, 1992, p.16). 


\section{POWER RELATIONSHIPS}

All negotiations are about the recognition and acceptance of power and the significance of agreement as well as a call for acknowledging differing dynamics of power transfer. Why would one start a negotiation if s/he doesn't need to negotiate; that is, doesn't have the feeling of some type of powerlessness?

Traditionally, the power in classroom was possessed by the institution and the educator in which students were the passive audience who were obliged to follow the rules and regulations imposed by these authority figures. A negotiated curriculum relates to the transaction of power in which parties are willing and prepared to transfer and bargain, barter, or negotiate their power. Why would the powerful part in a relationship be willing to share his or her authority with the powerless? More specifically, why would educators, representing and working in the name of educational institutions and traditionally occupying the role of the powerful, be willing to transmit their privilege of possessing power and distribute their strength? One reason is because the central foremost objective of the educators and their institution is to provide ultimate supreme learning environments for their enrolled students as this is the very reason of their existence. Accordingly, following all necessary means directing to a better learning environment is precisely relating to their actual goals and subsistence. This is because active learning would generate deep learners which then would assist educators attaining the goal of the provision of an excellent learning environment. Another reason is about the changing role of power; that is, with the increased competitiveness in the higher education sector, it is vital for institutions to keep up the number of enrolled students which is a warranty for their profitability and persistence. Most of higher education in capitalist and developed countries subsists with the enrolment fees of currently enrolled and potential students. To be able to attract and appeal to new enrolments, a higher educational institution has to attain a reputable name. One of the major components of this achievement is keeping content academic staff with their research and teaching capabilities and satisfied students who would spread positive word-of-mouth. This necessity had led these institutions to improve their learning environment with feedback from students via students' evaluations on teaching staff and quality of courses. Such practices were not employed historically. All these incidents indicate a shift in power from the institution and its educators toward its students. Institutions are interested in keeping better educators to preserve and improve their quality, reputation and appeal and educators want better scores on their subject evolutions and hence want to run smoother classroom environments with all parties involved content with the education. This is one of the reasons why these two previously-more-powerful parties, the institution and the educator, accept to negotiate with the in the past-lesspowerful party, the students.

This very decision of sharing or transferring power involves taking risks because the outcome will be a compromise and may result in conflicts of interest, yet, will allow both parties be mutual learners (Hodgkin, 2007).

Once the educator agrees on occupying the role of facilitator rather than directing choice, s/he will accept to be a process assistant and a resource linker without abandoning the roles of being a supplier of ideas, a provider of information, an expert and a supervisor (Boomer 1992).

\section{WHAT IS NEGOTIATED CURRICULUM?}

Conventionally, educators or an external accredited body determine the curriculum and the assessment types (Boud, 1992) in which some educators may see the student as a member of a continual flow of individuals who come into and depart class rooms (Powell, Farrer, and Cohen, 1985) and who are mostly difficult to be motivated (Wehlage, Rutter, Smith, Lesco, and Fernandez, 1989). To increase the motivation in the classrooms and creating research active students, as most leading universities place in their top graduate attributes, all participants of the education should be involved in the whole decision making process. One way of involving all parties into decision making is through negotiation with regard to various components of the curriculum (Brew and Barrie, 1999) via the means of student-centred curriculum integration in order to manage the tension between parties. A negotiated curriculum may be perceived as adaptation in the context of international business as opposed to standardization. Consistent with the adaptation theory in international business students tailor some components of the curriculum according to their needs and wants. This process will create individualized education (Horrocks, 2001). Subsequently, the individuality of students will be secured and respected and the pitfalls of forceful similarity in the form of general training will be overcome (Horrocks, 2001; Sequin, 1907,1866). 
The concept of negotiated curriculum stems from the idea that students must be supported in making choices and selection decisions with reference to curricular objectives, contents of the subject matter, in and out class room activities, methodology, resources, materials, and means of assessment. To do so, students should be involved in decision making process of curricula development. Curricula development is about determining the following matters and answering five major questions. (1) What are the objectives of the unit of study from the institution's perspective, and students' goals in choosing a specific course? This is about answering the succeeding questions by both parties. Why does the institution place this course into its education programme? And why do students select this course? (2) What is expected to be learned during this course to achieve the goals of both the institution and the students? That is, in terms of the learning material, topic, and theme to proceed, what is the desired outcome? (3) How will this topic be taught and learned? What teaching and learning style, methodology will be applied? Is it going to be in traditional lecture style, seminar style, distant learning, computer-based learning and so forth? What will be the student learning and teaching activities? (4) What sorts of material and resources will assist students in their learning experience? For example, which textbook will be followed (if any), or what will be reading material? (5) How will the students be evaluated with regard to the knowledge gathered during this course? What kind of assignments will be expected? How should the exams be like? Any other assessment types?

In order to involve students to this activity all parts, the institution, the educator and students should be willing to do so and share risk and responsibilities. The activity of designing altogether a curriculum proceeds like a solution of a business problem in a real firm. This also involves answering some questions like (1) where are we now? (2) Where do we want to go and be? (3) How do we go there? What is the job distribution? Who is responsible from various parts of the task at hand? Timing, when? Finally, (4) how will we find out that we achieved the desired outcome? How do we measure we are there? In the context of a unit of study this will translate into (1) what do we know already (or do not know) with regard to the topic? (2) What do we want to know additionally? What kinds of questions do we have we are curious about and want to be answered? (3) How will we answer them, what resources shall we use, how is the distribution responsibilities and activities, who will do these activities? (4) How will we display what we have learned? (Boomer, Lester, Onore, and Cook, 1994).

\section{IMPLICATION OF NEGATION CURRICULUM INTO ASSESSMENTS}

Consistent with the literature noted earlier, we educators are no doubt aware that each student has different methods for learning which works best for her/him, and each student may be different in her/his capability in displaying her/his knowledge. Additionally, students will be more involved in the learning activities if they are based on students' preferences according to their expertise, experiences, interests, strengths, or career expectations.

Educational objectives embrace all-time learning, worldwide interaction, meta-cognitive knowledge and capabilities. Hence, some new and different processes have to be employed. One of the key processes is Negotiated Curricula (Davenport, Jaeger, and Lauritzen 1995; Felix, 2005). This process highlights the difference of novel education understanding from the traditional teaching perspectives and will enhance the characteristics of contemporary education which include flexibility, breadth, cooperation, authenticity, relevance and wide-ranging organizational borders (Felix, 2005).

These arguments were my motive for employing "Negotiated Curricula" for student assignments. I employ negotiated curricula in my Global and International Marketing MKTG6013 course, for example, as follows. Students have the freedom to choose one of the assignments over others containing either (1) a case writing project by exploring a recent issue (through research in the Internet, newspapers etc.) about the internationalization experience of a firm and writing down an original case; or (2) a project on the internationalization experience of a local firm (e.g., first time market entrance to a foreign market; expansion in existing foreign markets; the international performance of a service firm...etc.); or (3) a composition of a scholarly essay; that is, a conceptual or research paper. These three different types of assignments are all significant for and relevant to the international marketing paradigm. However, students are expected to pick just one of them according to their preferences based on their experiences, interests, strengths, or career expectations.

As noted earlier, there are three different assignment types and two different exam types (a case study analysis with subsequent questions or short-questions type exam) for students to choose from. Moreover, they are 
also free in completing these assignments on individual bases or in teams. Specifically, this opportunity not only allows students to choose from three alternative assignments and two alternative exam types, but (it) also allows students to prefer an individual work above team studies and vice versa as per their desire. This is called Negotiated Curricula because it provides students with the opportunity to cooperate and agree on how they would prefer to study, spend their learning time and be assessed. I apply this in both my postgraduate courses: Global and International Marketing MKTG6013 and Services Marketing MKTG6103 for three years.

\section{THE NEGOTIATED ASSIGNMENTS}

The students were given in the first lecture very clear instructions on how to approach the negotiation. It was thoroughly explained that they first need to decide on which type of assignment they are interested in and then whether they prefer to proceed alone or in teams of 2-3 students. After finishing the written project they had to introduce it in an oral, stand-up presentation in class and manage a class discussion around it on a nominated day and time at the end of semester. Students in the audience were required to actively participate in classroom discussion of the project. The project, due one week prior to the scheduled presentation day, accounted for $30 \%$ and the presentation $10 \%$ of the overall marks in the unit of study. Students were explained on their choices with the use of the assignment option diagram which was written in their unit of study outline in detail and briefed in the first lecture via the means of power points slides.

\section{Assignment Option \# 1: Exploring and Writing a Case}

\section{Objective}

Students will gain an appreciation of business planning decisions. This assignment puts the students in the role of actual entrepreneurs or managers in real business scenarios. This task is designed for students to demonstrate their understanding of the key concepts of the unit and their ability to apply these concepts in order to improve the performance of a multinational firm. The project is intended to assist students integrate and apply theories and concepts they have learned in class into a real world context. This project can besides create stronger links between educational institutions and the business community. If students choose to complete this project in small teams it will assist them develop communication and collaborative skills, as well as enhance peer learning by encouraging deeper discussions of the unit's concepts between students. Nevertheless, students are also permitted to complete this project on individual basis.

Specifically, this piece of project is about identifying an international issue of a firm and writing student's own original case study around this issue. Students are expected to write their own particular case of an international marketing problem currently (or recently) facing a firm of interest, using the Big Picture analytical framework. For example, a shift in the marketplace, a new competitive threat, the marketing of a new product, the management of a new strategic partnership, the appropriate reaction to a business decline. To accomplish this task, students will complete a review for the internationalization of a real firm (local or international) of their choice. The corporation may be a local firm intending to go international or being threatened by international competition/firms or a multinational organization, international product category, product, brand or service. However, the core matter which the case will be written around should be related to an international issue. Hence the problem, failure, success or any issue under consideration should possess an international substance and significance. The case study should describe a firm's organizational scenario (international issue) that integrates material covered in the course; for example, obstacles (which occur due to being or intending to be international, or being threatened or affected by other internationals). That is, students are asked to seek, identify, develop, create and accordingly write a case scenario on their own. The case must be an own-created (i.e., identified) but an actual and valid organisational scenario (a real and existing firm and an actual problem). The project has to be an original piece of work. Cases should provide real world examples of companies who have demonstrated some of the theories that are illustrated in the book or in other resources. 


\section{Assignment Option \# 2: Foreign Market Entry Marketing Plan-Int'l Mktg Venture}

\section{Objective}

Students will gain an appreciation of business planning decisions. The business studied can also understand of its capabilities in potential overseas markets. This project can besides create stronger links between educational institutions and the local business community.

This assignment is about the internationalization analysis of a/the firm (students have visited-if they did), brand, product or a product category etc. They are asked to pick a business concept and develop a strategy for foreign expansion. International business plans should consider elements such as business capability, market research, market entry strategy, marketing strategy and international business administration. In complementing this project, students are expected to consider their team as a group of marketing research experts/analysts who have been given the task of designing this global expansion strategy.

Foreign Market Entry Marketing Plans consist of four parts: (1) Identification of the business (concept). The business concept may be (a) brand new international business concept - a new business idea which is not yet operating locally., or (b) new to international business - an existing local business that is not yet selling overseas; or (c) expanding markets - currently doing business overseas and planning to expand into another market that has sales opportunities for the business they pursue. (2) Selecting attractive country markets and quantifying industry market potential. (3) Screening for and choosing qualified foreign business partners. Finally, (4) structuring the business relationship with the foreign partner and preparing a comprehensive international market entry plan.

\section{Assignment Option \# 3: Scholarly Essay - Writing your Own Article}

\section{Objective}

Students will gain an appreciation of international businesses by deeply investigating matters affecting them with the use of theories and research. This assignment puts the students in the role of a scholar who investigates, thinks, argues and writes his views down in an intellectually and academically accepted format. This assignment is designed for students to demonstrate their understanding of the key concepts of the unit and their ability to apply these concepts in the context of a (multinational) argument. The project is intended to assist students integrate and apply theories and concepts they have learned in class into a scholarly essay. This project can besides create stronger links between the student and educational institutions. As it will be completed individually it will enhance students critical thinking, independency, creativity, and ability to structure their thoughts into careful sentences.

This is an individual project (max. two students exceptionally) and an alternative to other assignment types. This assignment is about writing a scholarly essay on a chosen topic in regards to international marketing which also has a research component (i.e., use of secondary or primary data, interviews, focus groups etc.) excepting conceptual essays founded on available theory. A conceptual piece of work without a research section may also be welcomed provided it creates a critique, a distinctive perspective or argument, a new model, theoretical idea etc. Selection of the topic should provide rationale for arguments and highlight relevant criteria/theory. Topics should use and be relevant to international marketing theories and studies. Students should select a topic which they are genuinely interested in or which relates to them in some manner (a career you are interested in, an industry you work for, a circumstance which you (may) face.

I recommend this choice for students who are either a native English speaker or have a perfect command of English; interested in reading and writing scholarly (essay or review type) articles or seminar papers; who may need them for their further academic pursue, such as an Honours, an MPhil, and/or a PhD degree; who are curious and interested in writing scholarly articles and therefore would like to try to write down independently and document their arguments in a methodologically recognized format; who have not decided whether they would enjoy academic work or studies and would like to find out; who would like to have a published article in a scholarly journal or an academic conference refereed proceeding (if the quality of the article/paper is good enough, and if the article is finished on time as a complete and proper research!); and/or who prefer individual assignments over group work. 


\section{THE NON-NEGOTIATED PART - THE PRESENTATION}

If the project was a team project each team member had to have a go in presenting with an equal share in terms of time and amount. That is, there was no negation with regard to presenting, each and every student had to present consistent with the universities graduate attributes emphasising the improvement of students' communication skills. Students were also informed in the first lecture about the criteria on which the presentation would be assessed. The first criterion was content related (50\%) including emphasis on important and related parts (as in the written project); quality of analysis and answers; originality, importance, breath and relevance of the project/case to marketing; and creativity (an interesting, exciting, fascinating or outstanding content). The second criterion was about the standard of the presentation (40\%) including introduction of team members in a professional manner; stating the structure of the presentation at the beginning; clarity and understandability; speech, confidence; appearance, body language, use of voice; no reading through the text or slides; humour, joy, fun, vivid (lively full of energy and dynamism) presentation; familiarity (of all group members) with content; evidence of group's consistent application to the task; and effective use of prompts, aids, technology and quality of PP slides. And finally the third criterion was about students' capability in leading a class discussion (10\%) including discussion management (interactivity, fairness and equal opportunity for class members to participate and overall leadership of class discussions); awareness of audience response; and time management of the presentation and class discussion (a proper share for both parts).

\section{DISCUSSION AND CONCLUSION}

Drawing largely from debates in the management education literature, this article discusses the possibilities of applying negotiated curriculum theory into marketing education practices and describes some strategies for implications in the marketing classroom.

Feedback from students indicates that students are very happy and content with the specified choice of selecting their assignment type. Out of 81 students in the last semester 11 have chosen an individual project. Among these 11 individual projects only 6 have selected the scholarly essay option. From the remaining 70 students 53 have chosen the case writing option. They said they find this option very creative and enjoyable. Some stated that they didn't want to do another extended marketing plan type assignment. Others said that they have done a similar assignment in the International Business course; hence, didn't want to duplicate an experience.

"It would be wrong to convey the impression that all students, or even a majority of them are willing and prepared to engage with the marketing the ways we have suggested." (Catterall, 2002, p. 190).

Forces of change, such as the shift of the power from educational institutions and educators to students and business firms, lead academics to redesign and improve their marketing curriculum innovation. This process involves several elements of the education system including "faculty commitment, consensus, collaboration, and compromise, stakeholder input, points of distinction, unifying themes, intended learning outcomes, instructional design, approval, a transition plan, and continuous improvement" (Borin, Metcalf and Tietje, 2007, p. 164).

\section{AUTHOR INFORMATION}

Dr Ulku Yuksel is an Assistant Professor in Marketing at the University of Sydney, since 2004. Dr Ulku Yuksel's research interests include cross-cultural marketing, international marketing and consumer behaviour. Specifically, culture, decision-making and consumption under risk, uncertainty, and stress, as well as anti-consumption and political marketing (e.g., boycott behaviour) are the sub-areas she is interested within this broad concept. Her recent researches explore people's (i.e., consumers' or entrepreneurs) evaluations and decisions as consumers involve in various levels and types of risks. Ulku Yuksel BA MU. MCom (Hons) ITU. PhD MU. GradCertEdStud (Higher Education) USYD. ulku.yuksel@sydney.edu.au. 


\section{REFERENCES}

1. Anderson, G., Boud, D. and Sampson, J. (1996), Learning contracts: A practical guide. London: Kogan Page.

2. Boomer, G. (ed) (1992), Negotiating the curriculum: Education for the $21^{\text {st }}$ century. New York: Taylor \& Francis Ltd.

3. Boomer, G., Lester, N., Onore, C., and Cook, J. (1994), Negotiating the curriculum: Education for the $21^{s t}$ century, London: Falmer.

4. Boud, D. (1992), "The use of self-assessment in negotiated learning", Studies in higher education, 17, 2 , pp.185-200.

5. $\quad$ Boud, D. (1988), Developing student autonomy in learning. $2^{\text {nd }}$ ed. London: Kogan Page.

6. Brew, A., Barrie, S. (1999), “Academic development through a negotiated curriculum", International Journal for Academic Development, 4, 1, pp. 34-42.

7. Catterall, M. (2002), "Critical reflection in the marketing curriculum", Journal of Marketing Education, 24, 3, pp. 184-192.

8. Davenport, M.R., Jaeger, M, and Lauritzen, C. (1995), "Negotiating curriculum,“ The Reading Teacher, 49 (1) September, pp. 60-62.

9. Feliz, U. (2005), "E-learning pedagogy in the third millennium: the need for combining social and cognitive constructivist approaches," ReCALL: the Journal of Eurocall, Cambridge University Press, 17 (1), pp. 85-100.

10. Hodgkin, M (2007), "Negotiating Change: Participatory Curriculum Design in Emergencies”, Current Issues in Comparative Education, 9 (2), pp. 33-44.

11. Honey, P. and Mumford A. (1986). A Manual of Learning Styles, Peter Honey, Maidenhead.

12. Horrocks, L. (2001), "The evaluation of the negotiated curriculum plan in South Australia", International Education Journal, Educational Research Conference 2001 Special issue, 2, 4, pp. 187-202.

13. Houghton, Warren (2004) Engineering Subject Centre Guide: Learning and Teaching Theory for Engineering Academics. Loughborough: HEA Engineering Subject Centre.

14. Knowles, M.S. (1975), Self-directed learning: a guide for learners and teachers. New York. Association Press.

15. Kolb, D. A. (1984). Experiential Learning, Prentice Hall.

16. McMahon, T. (2010). Combining peer-assessment with negotiated learning activities on a day-release undergraduate-level certificate course (ECTS level 3). Assessment and Evaluation in Higher Education, 35(2), 223.

17. Powell, A.G., Farrar, E, and Cohen, D.K., (1985), The shopping mall high school: Winners and losers in the educational market place. Boston: Houghton Mifflin.

18. Sequin, E., (1907), Idiocy: and its treatment by the physiological method. Albany, New York: Brandow Printing (original published in 1866).

19. Wehlage, G.G., Rutter, R.A., Smith, G.A., Lesco, N., and Fernandez, R.R., (1989), Reducing the risk: schools as communities of support. New York: Falmer. 